\title{
Intraneural ganglion cysts: a systematic review and reinterpretation of the world's literature
}

\author{
Nicholas M. Desy, MD, FRCS(C), ${ }^{1}$ Huan Wang, MD, PhD, ${ }^{2}$ Mohanad Ahmed Ibrahim Elshiekh, MD, ${ }^{3}$ \\ Shota Tanaka, MD, ${ }^{4}$ Tae Woong Choi, MD, ${ }^{5}$ B. Matthew Howe, MD, ${ }^{6}$ and Robert J. Spinner, MD ${ }^{1,2}$ \\ Departments of ${ }^{2}$ Neurologic Surgery, ${ }^{6}$ Radiology, and ${ }^{1}$ Orthopaedic Surgery, Mayo Clinic, Rochester, Minnesota; ${ }^{3}$ Department \\ of General Surgery, New York Methodist Hospital, New York City, New York; ${ }^{4}$ Department of Neurosurgery, Faculty of Medicine, \\ The University of Tokyo, Japan; and ${ }^{5}$ Department of Physical Medicine and Rehabilitation, Korea University Anam Hospital, \\ Seoul, Republic of Korea
}

OBJECTIVE The etiology of intraneural ganglion cysts has been controversial. In recent years, substantial evidence has been presented to support the articular (synovial) theory for their pathogenesis. The authors sought to 1) perform a systematic review of the world's literature on intraneural cysts, and 2) reinterpret available published MR images in articles by other authors to identify unrecognized joint connections.

METHODS In Part 1, all cases were analyzed for demographic data, duration of symptoms, the presence of a history of trauma, whether electromyography or nerve conduction studies were performed, the type of imaging, surgical treatment, presence of a joint connection, intraneural cyst recurrence, and postoperative imaging. Two univariate analyses were completed: 1) to compare the proportion of intraneural ganglion cyst publications per decade and 2) to assess the number of recurrences from 1914 to 2003 compared with the years 2004-2015. Three multivariate regression models were used to identify risk factors for intraneural cyst recurrence. In Part 2, the authors analyzed all available published MR images and obtained MR images from selected cases in which joint connections were not identified by the original authors, specifically looking for unrecognized joint connections. Two univariate analyses were done: 1) to determine a possible association between the identification of a joint connection and obtaining an MRI and 2) to assess the number of joint connections reported from 1914 to 2003 compared with 2004 to 2015.

RESULTS In Part 1, 417 articles (645 patients) were selected for analysis. Joint connections were identified in 313 intraneural cysts (48\%). Both intraneural ganglion cyst cases and cyst recurrences were more frequently reported since 2004 (statistically significant difference for both). There was a statistically significant association between cyst recurrence and percutaneous aspiration as well as failure to disconnect the articular branch or address the joint. In Part 2, the authors identified 43 examples of joint connections that initially went unrecognized: 27 based on their retrospective MR image reinterpretation of published cases and 16 of 16 cases from their sampling of original MR images from published cases. Overall, joint connections were more commonly found in patients who received an MRI examination and were more frequently reported during the years 2004 to 2015 (statistically significant difference for both).

CONCLUSIONS This comprehensive review of the world's literature and the MR images further supports the articular (synovial) theory and provides baseline data for future investigators.

http://thejns.org/doi/abs/10.3171/2015.9.JNS141368

KEY WORDS intraneural ganglion cyst; intraneural ganglia; articular (synovial) theory; systematic review; peripheral nerve

I

NTRANEURAL ganglion cysts are benign mucinous lesions that are formed within peripheral nerves and typically lead to symptoms and signs of peripheral neuropathy. Their pathogenesis has been controversial. Different treatments have been recommended. Outcomes have been disappointing and the recurrence rate high and underreported.
Over the past 15 years, our group has provided substantial evidence to support a unifying articular (synovial) theory as the etiology for all intraneural ganglion cysts. In 2003, the senior author (R.J.S.) demonstrated that the prototypical intraneural cysts of the common peroneal nerve are joint derived. Cyst formation originates in the superior tibiofibular joint (STFJ) and propagates toward

ABBREVIATIONS EMG = electromyography; NCS = nerve conduction studies; STFJ = superior tibiofibular joint.

SUBMITTED July 1, 2014. ACCEPTED September 10, 2015.

INCLUDE WHEN CITING Published online January 22, 2016; DOI: 10.3171/2015.9.JNS141368. 
the parent (common peroneal) nerve through its articular branch (Fig. 1). ${ }^{124,125}$ Since then, the articular (synovial) theory has been further substantiated by our group and others at many other nerves at several other anatomical locations. ${ }^{13,19,82,102,113,114,117,118,135,143,144,147,153,170,173}$ Three principles for these cysts have emerged: 1) intraneural ganglion cysts are formed from a capsular defect of a neighboring joint, which allows joint fluid to egress and track along the epineurium of an innervating articular branch; 2) the fluid follows the path of least resistance; and 3) the cyst takes form due to changes in pressure and pressure fluxes. ${ }^{122}$ These underlying principles of the articular theory explain the stereotypic patterns of formation that have best been described for peroneal and tibial intraneural cysts arising from the STFJ.

We sought to perform a systematic review of the world's literature to summarize the current state of our understanding of intraneural ganglion cysts and to provide a baseline for future investigators. A global perspective is lacking due to the relative rarity of these lesions and their publication mostly as isolated case reports. Other than a large review of intraneural cysts of the upper extremity, ${ }^{170}$ we are unaware of an encompassing summary of cases of intraneural ganglion cysts.

As proponents of the unifying articular theory, we also wanted to reinterpret the available MR images to look for unrecognized joint connections, which we believe should exist for all cases. Ultimately, as the awareness and understanding of this theory becomes more widely circulated, joint connections should be increasingly recognized, abolishing the existing controversy regarding etiology.

\section{Methods}

\section{Part 1. Literature Review}

\section{Inclusion Criteria}

The aim of this study was to collect and review the world's literature on intraneural ganglion cysts published over the past century. For the purposes of the study, inclusion criteria were 1) published articles or published abstracts that reported a case series or case report on appendicular intraneural ganglion cyst(s) since 1914 (inclusive); 2) review articles that included a case or cases with some patient characteristics, such as age, sex, etc., which in some instances were provided in the figure legends; 3) letters to the editor that provided new information on a reported case; and 4) articles published in any language. Exclusion criteria consisted of 1) all articles that did not specifically report on a patient with an intraneural ganglion cyst (review articles that only showed an image of an intraneural cyst and did not provide any patient information, letters to the editor that did not report new information on a case, and textbook chapters); 2) examples of extraneural ganglion cysts; 3 ) reports of spinal and cranial intraneural cysts, which have been controversial; $8,15,34,36,40,94,123,126,140$ 4) cases of an intraneural cystic lesion that contained a pathology determined not to be an intraneural ganglion cyst or those published before 1914 as a pathological diagnosis of earlier cases could not be assured; and 5) unpublished conference abstracts. Of note, while those articles that were excluded based on the first exclusion criterion above were
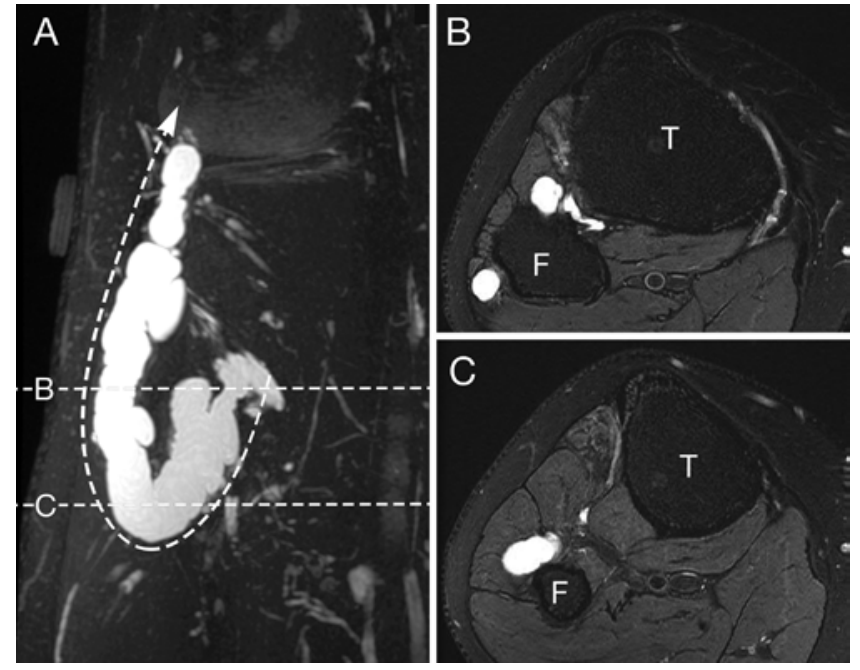

FIG. 1. Typical example of a peroneal intraneural ganglion cyst with a connection to the STFJ (unpublished case, not included in this analysis). The coronal maximum intensity projection MR image from a T2-weighted fat-saturated sequence (A) demonstrates the classic "U" pattern in a peroneal intraneural ganglion cyst arising from the STFJ (dashed arrow). The axial T2-weighted fat-saturated MR image through the level of the fibular head (B) demonstrates cyst within the common peroneal nerve (signet ring sign). There is intraneural cyst near the STFJ and joint fluid in the joint itself. ${ }^{146}$ The axial T2-weighted fat-saturated image through the level of the fibular neck $(\mathbf{C})$ demonstrates intraneural cyst within the articular branch (transverse limb sign). $F=$ fibula; $T=$ tibia.

eliminated from the data analysis, some information from those articles was included in our overall study.

\section{Literature Search}

An extensive literature search was performed using multiple scientific databases (PubMed, Scopus, Embase, Quertle, Google, Google Scholar, CiNii, J-Stage, Science Links Japan, KoreaMed, and KoMCI). Search terms included "intraneural ganglion cyst", "intraneural ganglia", "intraneural cyst", and "intraneural cystic degeneration." The reference section of each article identified was also analyzed for additional reports. The search ended April $1,2015$.

\section{Study Selection}

Selected studies were those that contained at least one of the 4 search terms. Articles that were found in the reference sections of selected studies but that did not necessarily contain one of the search terms were also included. The reports were read in detail to confirm the presence of at least one case of an intraneural ganglion cyst or new information on a previously reported patient. Duplicate case reports were identified for exclusion as well as articles that did not mention a patient with an intraneural ganglion cyst.

\section{Data Extraction}

Aspects of each publication, which consisted of the first author, year of publication, and written language were recorded. Demographic data included patient age, sex, side of the body that was affected, and nerve involved. Symp- 
tom duration as well as a history of trauma was also extracted. It was noted if patients underwent electromyography (EMG) or nerve conduction studies (NCS) as well as imaging, including radiography, ultrasonography, computed tomography (CT), and MRI. The presence of an arthrogram was also determined. Additional data included: the type of surgical treatment, the identification of a joint connection, amount of follow-up, development of an intraneural cyst recurrence, and whether any postoperative imaging was performed. The number of intraneural recurrences and joint connections were analyzed twice in 2 different groups: 1) all publications identified for analysis and 2) all articles excluding those associated with the senior author (R.J.S.). A translator was used to help with data extraction for all articles published in a language other than English or French.

\section{Statistical Analysis}

To assess the proportion of published intraneural ganglion cysts over time, the study period was categorized into 2 eras: 1) cases published from 1914 to 2003 and 2) cases reported from 2004 to 2013. Using a single-sample chi-square test, the proportion of cases reported from 2004 to 2013 (inclusive) was compared with the expected proportion of $10 \%$ under the null hypothesis (since 2004 to 2013 represents $10 \%$ of the total 100 -year study period). A chi-square test was used to assess the comparative absolute numbers of published intraneural ganglion cyst recurrences within 2 groups covering the entire study period: 1) 1914-2003 and 2) 2004-2015. The designated year for each cyst recurrence was given according to the year that the intraneural cyst was first reported. Three separate multivariate logistic regression models were used to identify risk factors for intraneural cyst recurrence. All 3 regression models used intraneural cyst recurrence or persistence as the dependent variable and patient age, sex, and type of surgery as the independent variables for cyst recurrence. A histogram was used to determine that age, which was the only continuous variable, had a normal distribution. The 3 analyses differed with respect to the type of surgery analyzed. The first multivariate regression analysis used 2 surgical treatment groups: 1) cases where surgical treatment did not disconnect the articular branch or address the joint and 2) cases in which the articular branch was disconnected or the joint was treated as part of surgery. The second multivariate analysis used the same treatment groups, while excluding all patients initially treated by the senior author of this systematic review to eliminate bias as much as possible. The third multivariate regression model separated the surgical treatment groups into 1) patients treated with open surgery and 2) patients treated with percutaneous aspiration. Only patients that had uniform data and reported follow-up were included in the analyses. Patients treated nonoperatively were excluded from all 3 multivariate analyses. Values were considered statistically significant with a $p$ value $<0.05$. All analyses were performed using JMP Pro 11 software (SAS Institute Inc.).

\section{Part 2. MRI Review}

All case reports that contained published MR images were reviewed. Evidence of joint connections was determined in cases in which the original authors did not report the identification of a joint connection and MR images were available within the published case report for our review. For the most common example, the peroneal nerve at the fibular neck, in particular, we used previously reported signs as being diagnostic, namely the tail sign (cyst at the STFJ) and transverse limb sign (cyst within the articular branch along the fibular neck), both of which have been shown to be highly sensitive and specific for detecting intraneural cyst joint connections. ${ }^{130}$ The secondary finding of cyst wrapping around the fibular neck (toward the articular branch) was considered suggestive (but not diagnostic) of an example of a joint-related intraneural ganglion. Several of these examples and our reinterpretations of the published images were published previously to support the articular theory, define its underlying principles, and demonstrate the utility of these radiological signs. ${ }^{113,114,128,170}$

In addition, 16 full series of original MR images from published cases were obtained from authors who did not identify a joint connection in their original publication and these images were reviewed. These cases had been randomly sampled over the past 15 years. Eleven of these cases and our reinterpretations were published. ${ }^{115,116,120,124,136 \text {, }}$ $143,144,147,153$

The MR image reviews were all done by a fellowshiptrained musculoskeletal radiologist and the senior author, a neurosurgeon, both highly experienced in evaluating intraneural ganglion cysts.

\section{Statistical Analysis}

A chi-square test was used to determine whether joint connections were more commonly identified when an MRI study was obtained as part of patient assessment. A chi-square test was also used to ascertain whether joint connections were reported more frequently since 2004 (2004-2015) compared with the first 90 years included in this study (1914-2003). A $p$ value $<0.05$ was considered statistically significant. The analysis was performed using JMP Pro 11 software (SAS Institute Inc.).

\section{Results \\ Part 1. Literature Review}

A total of 640 papers were identified following the initial search across all databases and article reference sections. Eighteen duplicate case reports were identified, 17 of which were excluded. ${ }^{6,26,46,60,67,71,97,111,121,131,134,135,158,163,165,168,172}$ The 1 duplicate case report that was included consisted of a retracted article, ${ }^{2,56}$ which contained information on 2 new cases and therefore remained for analysis. Twentythree articles were excluded during the screening process because they were published prior to 1914. After carefully reading each article for eligibility, 172 papers were excluded because they either did not provide a case report $(\mathrm{n}=73)$, the lesion was an extraneural ganglion cyst $(\mathrm{n}=$ $69)$, they described a spinal $(n=2)$ or cranial intraneural cyst $(\mathrm{n}=6)$, or the pathology presented differed from a ganglion cyst $(\mathrm{n}=22)$. Eight case reports were considered indeterminate and were also excluded because a diagnosis 


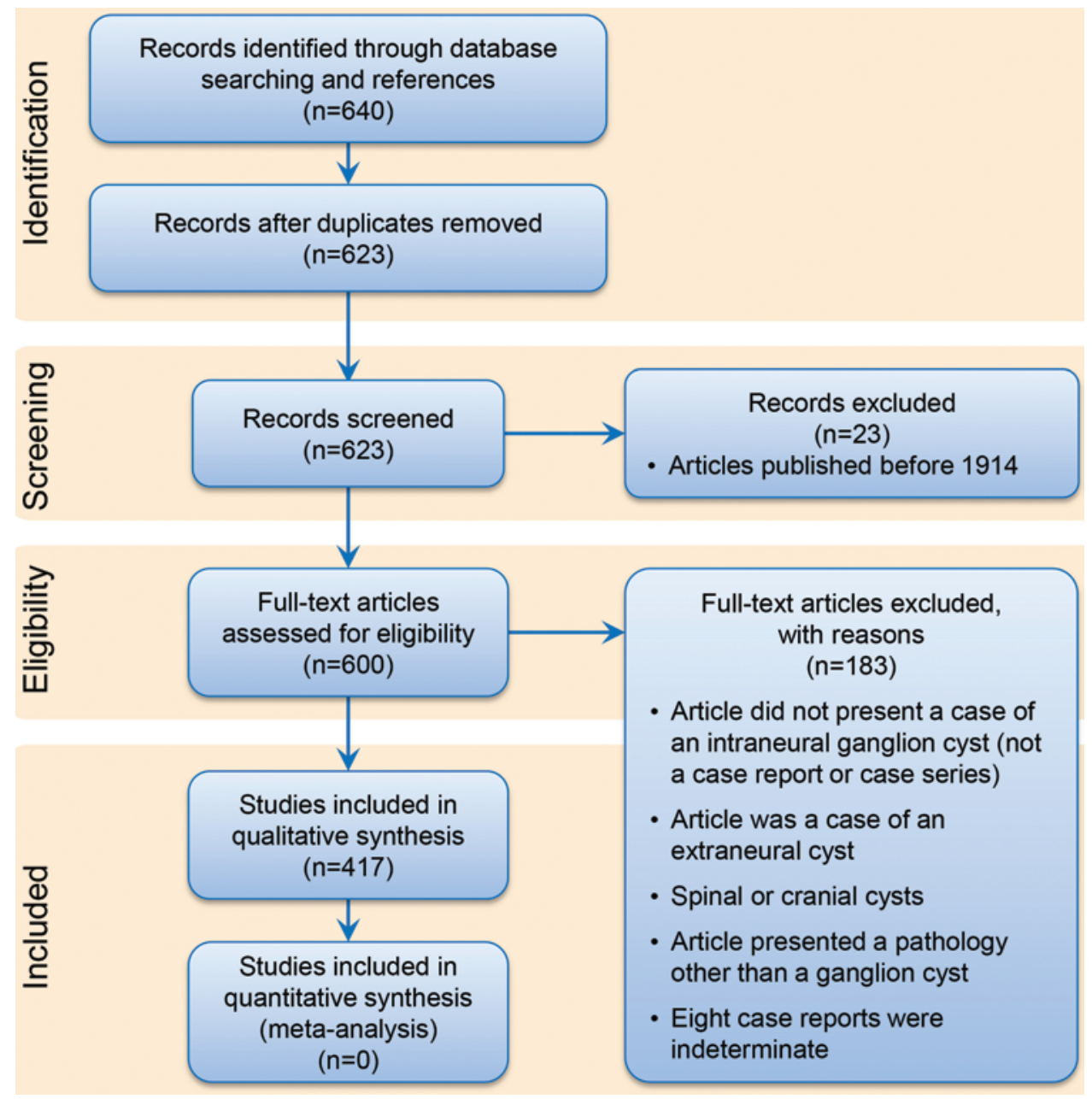

FIG. 2. Preferred Reporting Items for Systematic Reviews and Meta-Analyses (PRISMA) 2009 flow diagram demonstrating our search strategy and study selection. Based on Moher D, Liberati A, Tetzlaff J, Altman DG, The PRISMA Group (2009): Preferred Reporting Items for Systematic Reviews and Meta-Analyses: The PRISMA Statement. PLoS Med 6:e1000097.

of an intraneural ganglion cyst could not be reached with certainty. $9,27,35,38,39,64,76,110$ Three articles that reported on a series of patients with ganglion cysts were excluded because it was not possible to distinguish between individual patients that had an intraneural or extraneural cyst. .77,49,65 $^{2}$ Finally, 417 articles remained for inclusion in the analysis (Fig. 2) (see online Appendix 1). The number of articles in each language is represented in Table 1.

\section{Patient Demographics and Nerves Affected}

The pooled demographic data from all cases are presented in Table 2 (645 patients with 648 cysts). As expected, the common peroneal nerve was the most common location affected by intraneural ganglion cysts overall (391 patients, 393 limbs), while the ulnar nerve and its branches were most frequently involved in the upper extremity, with a total of 93 cysts at all sites of the upper extremity (Fig. 3).

\section{Patient Management and Follow-Up}

A total of 368 patients underwent either EMG or NCS.
A variety of imaging studies were performed as part of patient assessments. An MRI study was completed for 297 patients. Of those patients that did not receive an MRI, 21 had a CT scan, 35 had an ultrasound examination, 9 had a CT scan and ultrasonography, 42 patients had only a radiograph, and 2 patients received only a plain arthrogram. In total, an arthrogram was obtained as part of the patient workup in 15 case reports (4 plain arthrograms, 3 CT arthrograms, and 8 MRI arthrograms). In 239 cases no imaging was reported.

Several treatment modalities have been reported in the literature for intraneural ganglion cysts (Table 3). Five patients with unilateral cysts were treated nonoperatively because they were either asymptomatic or mildly symptomatic or the cyst had resolved spontaneously, and 1 limb of each of the 3 bilateral cases was also treated nonoperatively due to a lack of symptoms. In 110 cases, specifically ligating or disconnecting the articular branch was reported as part of the surgical strategy, and in 2 of these cases ligation of the articular branch was the sole treatment. ${ }^{77,153}$ In 23 of those cases in which the articular branch was addressed, the associated joint was also treated (STFJ resec- 
TABLE 1. Number of articles that were reviewed in each language for data extraction (417 articles; 645 patients with 648 cysts)

\begin{tabular}{lc}
\hline Language & No. of Articles \\
\hline Afrikaans & 1 \\
\hline Chinese & 7 \\
\hline Czech & 1 \\
\hline Danish & 1 \\
\hline English & 238 \\
\hline French & 19 \\
\hline German & 27 \\
\hline Hungarian & 1 \\
\hline Italian & 11 \\
\hline Japanese & 68 \\
\hline Korean & 19 \\
\hline Polish & 4 \\
\hline Portuguese & 2 \\
\hline Russian & 1 \\
\hline Spanish & 14 \\
\hline Thai & 1 \\
\hline Turkish & 2 \\
\hline
\end{tabular}

tion). In another 2 reports the joint was targeted primarily without necessarily treating the articular branch during surgery (STFJ resection with cyst resection and hip joint offset procedure with labral repair).

Follow-up was inconsistently reported, with $76 \%$ of cases providing a time of follow-up (average 26 months, range $0.5-420$ months). Follow-up imaging was obtained in only 94 reports (15\%) and consisted of MRI (in 74 cases), MRI arthrogram (in 1), ultrasonography (in 13), all 3 tests (in 1), MRI and ultrasonography (in 3), a plain arthrogram (in 1), and MRI with a plain arthrogram (in 1). In those that reported follow-up, the patients' clinical condition improved subsequent to treatment in 376 cases (76\%), remained unchanged in 47 cases $(10 \%)$, and worsened after surgery in 5 cases (1\%); in 65 cases (13\%), clinical outcomes were not reported.

\section{Joint Connections}

All 648 intraneural cysts were para-articular. Overall, 313 joint connections (48\%) were identified in the literature (Table 4) (see online Appendix 2). Two hundred eighty-four of those connections were found during the initial management, and 29 were discovered subsequent to cyst recurrence on follow-up MRI or at revision surgery. The joints with reported intraneural cyst connections include: glenohumeral joint (4 cases), ulnohumeral joint (18), distal radioulnar joint (2), radiocarpal joint (1), carpal joints (8), carpometacarpal joint (3), thumb metacarpophalangeal joint (1), thumb interphalangeal joint (2), acetabulofemoral joint (10), tibiofemoral joint (12), STFJ (221), inferior tibiofibular joint (2), tibiotalar joint (5), subtalar joint (16), calcaneocuboid joint (1), and metatarsophalangeal joint (1). Six reports did not specify the joint that had a connected intraneural cyst. When the publications of the senior author were excluded, 238 joint connec-
TABLE 2. Patient demographic and clinical characteristics*

\begin{tabular}{|c|c|c|c|}
\hline Characteristic & Pediatric & Adult & Total \\
\hline No. of pts (no. of cysts) & $84(84)$ & $535(538)$ & $645(648)$ \\
\hline Mean age (range) in yrs & $12(4-17)$ & $44(18-76)$ & $40(4-76)$ \\
\hline \multicolumn{4}{|l|}{ Sex, no. of pts (\%)† } \\
\hline Male & $65(79)$ & $361(73)$ & $429(74)$ \\
\hline Female & $17(21)$ & $136(27)$ & $153(26)$ \\
\hline \multicolumn{4}{|l|}{ Limb side } \\
\hline Right (\%) & $25(30)$ & $186(35)$ & $213(33)$ \\
\hline Left (\%) & $38(45)$ & $156(29)$ & $195(30)$ \\
\hline Bilateral (\%) & $0(0)$ & $3(0.6)$ & $3(0.5)$ \\
\hline Not reported (\%) & $21(25)$ & $190(36)$ & $234(36)$ \\
\hline History of trauma (\%) & $22(26)$ & $64(12)$ & $87(13)$ \\
\hline $\begin{array}{l}\text { Mean symptom duration } \\
\text { (range) in mos }\end{array}$ & $7(0.1-96)$ & $13(0.1-240)$ & $12(0.1-240)$ \\
\hline \multicolumn{4}{|c|}{$\begin{array}{l}\text { pts = patients. } \\
\text { * The age was not reported for } 26 \text { patients. They were excluded from the } \\
\text { pediatric and adults subgroups, but counted in the total group. } \\
\text { † The sex was not reported for } 2 \text { patients in the pediatric subgroup, } 38 \\
\text { patients in the adult subgroup, and for } 63 \text { patients overall. }\end{array}$} \\
\hline
\end{tabular}

tions $(40 \%)$ were reported. In 27 of the 74 recurrences a joint connection was not identified at the time of the initial evaluation and treatment, retrospectively (by the original authors), or at revision surgery.

\section{Recurrences}

At least 1 cyst recurrence or cyst persistence occurred in 74 patients (11\%) overall (Table 5) (see online Appendix 3 ), with 8 of those patients having 2 or more recurrences. Three recurrences were reported following ligation of the articular branch as part of the initial surgery. ${ }^{12,84,85}$ There were 5 recurrences that occurred from cysts in the upper extremity and 69 following the treatment of cysts in the lower extremity. When the patients initially treated by the senior author were excluded, a recurrence rate of $12 \%$ was determined.

\section{Statistical Analysis}

The single-sample chi-square test determined that intraneural ganglion cysts were reported statistically significantly more frequently within the years 2004-2013 compared with the expected $10 \%$ number of cases under the null hypothesis ( $\mathrm{p}<0.0001)$. The chi-square test identified that recurrences were more commonly reported in the years 2004-2015 (20\%) as compared with the years $1914-2003(10 \%)(p=0.0039)$. Based on the multivariate logistic regression analyses, failure to disconnect the articular branch (cystic joint connection) or failure to address the joint is a statistically significant risk factor for cyst recurrence (OR 5.3, 95\% CI 1.9-22.2, p = 0.0006) (Table 6). Failure to treat the articular branch or joint remained as a statistically significant risk factor for cyst recurrence when those cases treated by the senior author were excluded (OR 4.1, 95\% CI 1.4-17.3, $\mathrm{p}=0.0059)$. Percutaneous aspiration is also statistically significant for cyst recurrence (OR 12.6, 95\% CI 2.4-93.8, p = 0.0035) compared with open surgical procedures (Table 7). Age is 


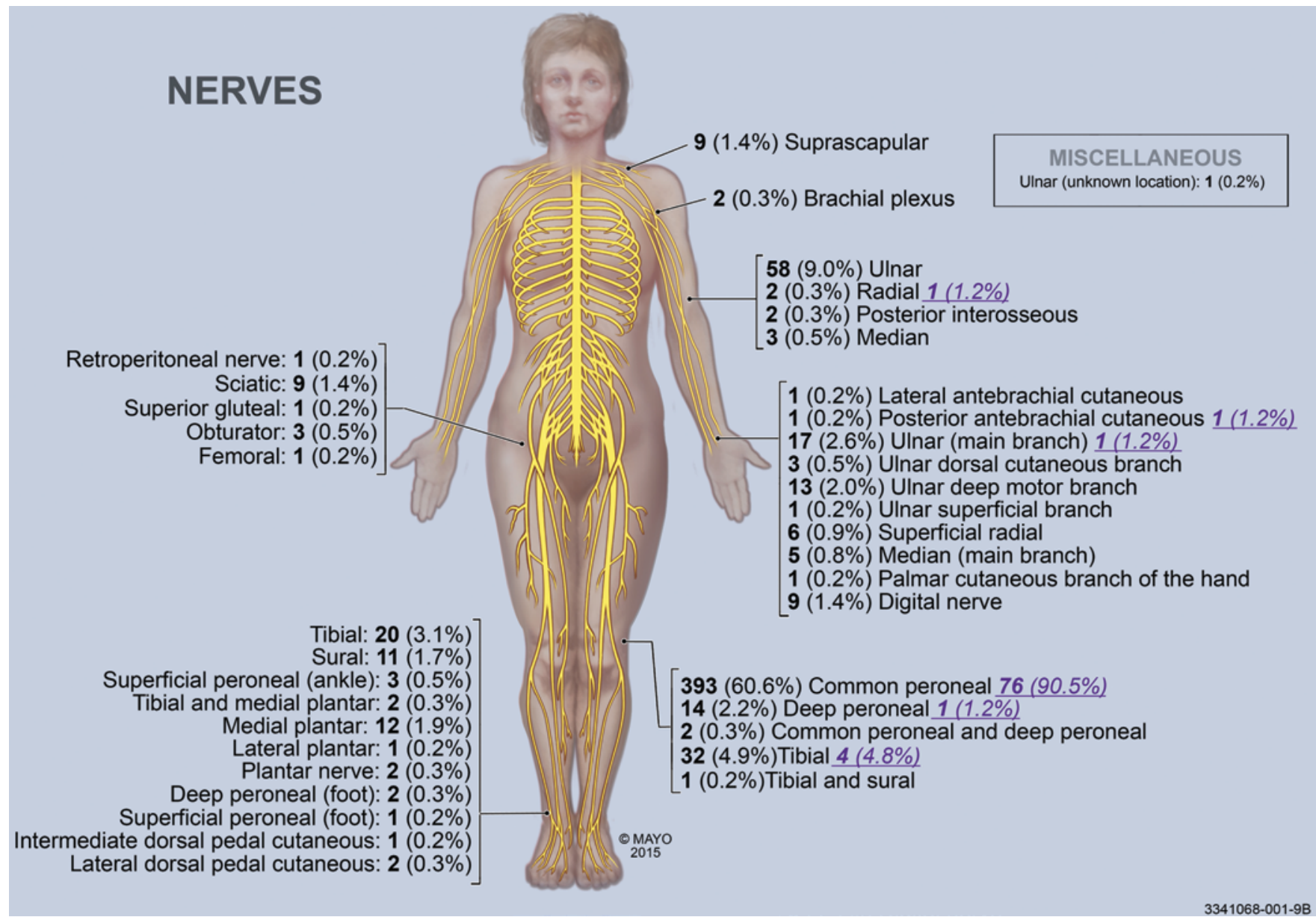

FIG. 3. Artistic illustration depicting the various neural sites of intraneural ganglion cysts reported in the world's literature. Numbers in black represent the total amount of cases, the underlined purple numbers correspond to pediatric cases. By permission of Mayo Foundation for Medical Education and Research. All rights reserved.

statistically significant when adjusting for sex and failure to ligate the articular branch or address the joint but did not reach significance when using percutaneous aspiration as the treatment method. Sex was not a statistically significant risk factor for cyst recurrence in all analyses (Tables 6 and 7).

\section{Part 2. MRI Review}

Of the 297 patients that underwent an MRI as part of their evaluation, 175 had joint connections reported by the original authors. The remaining 79 cases with published images were all reviewed for possible joint connections. By reviewing these images, we were able to identify joint connections in 27 case reports of intraneural ganglia that were previously unrecognized prospectively by others: glenohumeral joint (1), ulnohumeral joint (2), thumb interphalangeal joint (1), STFJ (20), inferior tibiofibular joint (1), and subtalar joint (2) (Fig. 4). 4,7,11,51,66,70,74,75,79,81,93,98,101,103,109,113,114, 128,154,156,157,170,174,176 Most of these joint connections were found in publications that provided several MR images and some were seen based on 1 or 2 published images. In another 4 cases, the findings were suggestive of joint connections to the STFJ, but no connection could be definitively confirmed given the limitations and number and quality of the available images. Based on our reinterpretation of these cases we found examples where intraneural cases were in fact extraneural; $, 5,87,101$ cysts described as extraneural were thought to be intraneural, ${ }^{41,42,53,59,92} 2$ cases that were unspecified appeared intraneural, $, 7,49$ as did 1 case of an inflammatory pseudotumor; ${ }^{31,32}$ and a tibial intraneural ganglion was actually a peroneal intraneural ganglion. ${ }^{63}$

Furthermore, of the 16 cases in which we were able to obtain the original full MRI series of select cases, ${ }^{18,22,99,100,}$ $109,115,116,120,124,136,143,144,147,153$ all had previously unrecognized joint connections: ulnohumeral joint (1), carpal joint (1), acetabulofemoral joint (3), tibiofemoral joint (4), STFJ (6), and tibiotalar joint (1) (Fig. 5). In 3 cases, MRI studies performed several years after surgical treatment demonstrated cyst recurrence with identifiable joint connections to the STFJ (in all 3 patients). ${ }^{68,115,122,141}$ In an additional case, our review of the original images led us to specify the joint connection (tibiofemoral), which was not included in the original text. ${ }^{62}$

\section{Statistical Analysis}

The chi-square test determined that joint connections 
TABLE 3. Treatment distribution*

\begin{tabular}{lccc}
\hline \multicolumn{1}{c}{ Type of Treatment } & Pediatric (\%) & Adult (\%) & Total (\%) \\
\hline Nonoperative & $0(0)$ & $8(1.5)$ & $8(1.2)$ \\
\hline Percutaneous aspiration & $1(1.2)$ & $3(0.6)$ & $4(0.6)$ \\
\hline Percutaneous aspiration \& steroid injection & $1(1.2)$ & $1(0.2)$ & $2(0.3)$ \\
\hline Decompression & $1(1.2)$ & $6(1.1)$ & $8(1.2)$ \\
\hline Cyst incision \& evacuation & $14(16.7)$ & $87(16.2)$ & $102(15.7)$ \\
\hline Partial cyst resection & $2(2.4)$ & $21(3.9)$ & $23(3.5)$ \\
\hline Partial cyst resection \& nerve graft & $0(0)$ & $1(0.2)$ & $1(0.2)$ \\
\hline Complete cyst resection & $40(47.6)$ & $284(52.8)$ & $329(50.8)$ \\
\hline Complete cyst resection \& nerve graft & $1(1.2)$ & $5(0.9)$ & $6(0.9)$ \\
\hline Nerve transfer & $0(0)$ & $1(0.2)$ & $1(0.2)$ \\
\hline Ligation of articular branch & $0(0)$ & $2(0.4)$ & $2(0.3)$ \\
\hline Ligation of articular branch \& STFJ resection & $0(0)$ & $2(0.4)$ & $2(0.3)$ \\
\hline Cyst incision \& evacuation \& ligation of articular branch & $8(9.5)$ & $33(6.1)$ & $46(7.1)$ \\
\hline Cyst incision \& evacuation, ligation of articular branch, \& STFJ resection & $1(1.2)$ & $14(2.6)$ & $17(2.6)$ \\
\hline Cyst resection \& ligation of articular branch & $7(8.3)$ & $31(5.8)$ & $39(6.0)$ \\
\hline Cyst resection, ligation of articular branch, \& STFJ resection & $2(2.4)$ & $2(0.4)$ & $4(0.6)$ \\
\hline Cyst resection \& STFJ resection & $0(0)$ & $1(0.2)$ & $1(0.2)$ \\
\hline Hip offset procedure \& labral repair & $0(0)$ & $1(0.2)$ & $1(0.2)$ \\
\hline Type of surgery not specified & $5(6.0)$ & $19(3.5)$ & $25(3.9)$ \\
\hline Treatment not reported & $1(1.2)$ & $16(3.0)$ & $27(4.2)$ \\
\hline The age was not & & & \\
\hline
\end{tabular}

* The age was not reported for 26 patients. They were excluded from the pediatric and adults subgroups but counted in the total group.

were more commonly identified when MRI was part of patient assessment (65\%) compared with joint connections that were found when an MRI was not obtained (33\%) (statistically significant difference, $p<0.0001$ ). It also found that joint connections were more frequently reported in the years 2004-2015 (69\%) compared with the first 90 years included in this study $(33 \%)(\mathrm{p}<0.0001)$. These numbers increased even more when the reinterpreted cases were included (75\% compared with $34 \%$ respectively, $\mathrm{p}<0.0001$ ).

\section{Discussion}

This comprehensive retrospective review and reinterpretation provides statistically significant data in 4 areas that we believe shed important information on intraneural ganglia.

1. Intraneural cysts are not rare. They are becoming diagnosed increasingly ${ }^{167}$ and reported more frequently now that imaging of nerves is being performed at a higher rate (Fig. 6).

2. Joint connections are becoming increasingly identified, especially in cases in which MRI is used (Fig. 6). Since the end of 2003, of the total amount of reported joint connections, a greater percentage of joint connections have been described, with $61 \%$ (191 joint connections, 73 from 2004-2008 and 118 from 2009-2015) being reported since this date.

3 . Intraneural recurrences are becoming increasingly recognized. We believe that this is due to the increasing awareness of joint connections, the increasing use of MRI and the better follow-up of these patients. We wish to emphasize that joint connections have been consistently identified when initial or postoperative images from these cases have been scrutinized. We predict that the percentage of intraneural recurrences will decrease as treatment paradigms change and target the articular branch connection (see number 4 below).

4. Failure to disconnect the articular branch or treat the joint pathology has been found to be a statistically significant risk factor for cyst recurrence.

\section{Etiology}

The etiology of intraneural ganglion cysts has been controversial. From the first case to more contemporary reports, we have proven that this theory applies, even when the original authors did not find a joint connection. The first known report and specimen of an ulnar intraneural ganglion cyst (1809) described by Beauchêne ${ }^{10}$ was recently rediscovered, reanalyzed, and shown to have evidence of an elbow joint connection (not included in the data analysis). ${ }^{150}$ A recent case by Choi and Kwon (2013) describing a tibial intraneural cyst in the popliteal fossa could be shown to have a joint connection to the knee on our reinterpretation (Fig. 5), though these authors did not find a joint connection..$^{22}$ For the intervening years, we have supplied ample evidence to support this theory: we found a joint connection on preoperative MR images in 27 cases where it was not previously identified; in some cases we found unrecognized cyst recurrence/persistence, ${ }^{116,122,141}$ contrary to the original published descriptions. The fact that we still could find many examples of unrecognized joint connections in other publications which only supplied a single 
TABLE 4. Number of joint connections per nerve affected*

\begin{tabular}{|c|c|c|c|}
\hline Extremity \& Nerve Affected (joint connection)† & Pediatric (\%) & Adult (\%) & Total $(\%)$ \\
\hline \multicolumn{4}{|l|}{ Upper extremity } \\
\hline Suprascapular (glenohumeral) & $0(0)$ & $4(44)$ & $4(44)$ \\
\hline Posterior interosseous (ulnohumeral) & $0(0)$ & $1(50)$ & $1(50)$ \\
\hline Ulnar (ulnohumeral) & $0(0)$ & $16(28)$ & $17(29)$ \\
\hline Median (radiocarpal or CMC) & $0(0)$ & $2(40)$ & $2(40)$ \\
\hline Ulnar (DRUJ or carpal) & $0(0)$ & $6(38)$ & $6(35)$ \\
\hline Ulnar deep motor branch (carpal or CMC) & $0(0)$ & $5(38)$ & $5(38)$ \\
\hline Digital (IP) & $0(0)$ & $4(44)$ & $4(44)$ \\
\hline Total & $0(0)$ & $38(29)$ & $39(29)$ \\
\hline \multicolumn{4}{|l|}{ Lower extremity } \\
\hline Sciatic (acetabulofemoral) & $0(0)$ & $7(78)$ & $7(78)$ \\
\hline Superior gluteal (acetabulofemoral) & $0(0)$ & $1(100)$ & $1(100)$ \\
\hline Obturator (acetabulofemoral) & $0(0)$ & $2(67)$ & $2(67)$ \\
\hline Common peroneal (tibiofemoral or STFJ) & $39(51)$ & $151(51)$ & $209(53)$ \\
\hline Deep peroneal (STFJ) & $1(100)$ & $4(36)$ & $7(50)$ \\
\hline Tibial (tibiofemoral or STFJ) & $4(100)$ & $18(64)$ & $22(69)$ \\
\hline Tibial (tibiotalar or subtalar) & $0(0)$ & $7(35)$ & $7(35)$ \\
\hline Superficial peroneal (ITFJ or tibiotalar) & $0(0)$ & $2(67)$ & $2(67)$ \\
\hline Tibial and medial plantar (subtalar) & $0(0)$ & $1(50)$ & $1(50)$ \\
\hline Sural (subtalar or calcaneocuboid) & $0(0)$ & $6(55)$ & $6(55)$ \\
\hline Medial plantar (subtalar) & $0(0)$ & $6(50)$ & $6(50)$ \\
\hline Lateral plantar (subtalar) & $0(0)$ & $1(100)$ & $1(100)$ \\
\hline Deep peroneal (MTP) & $0(0)$ & $1(50)$ & $1(50)$ \\
\hline Superficial peroneal (region of ankle or foot not specified) & $0(0)$ & $1(100)$ & $1(100)$ \\
\hline Intermediate dorsal pedal cutaneous (tibiotalar) & $0(0)$ & $1(100)$ & $1(100)$ \\
\hline Total & $44(54)$ & $209(51)$ & $274(53)$ \\
\hline Grand total & $44(52)$ & $247(46)$ & $313(48)$ \\
\hline \multicolumn{4}{|c|}{ 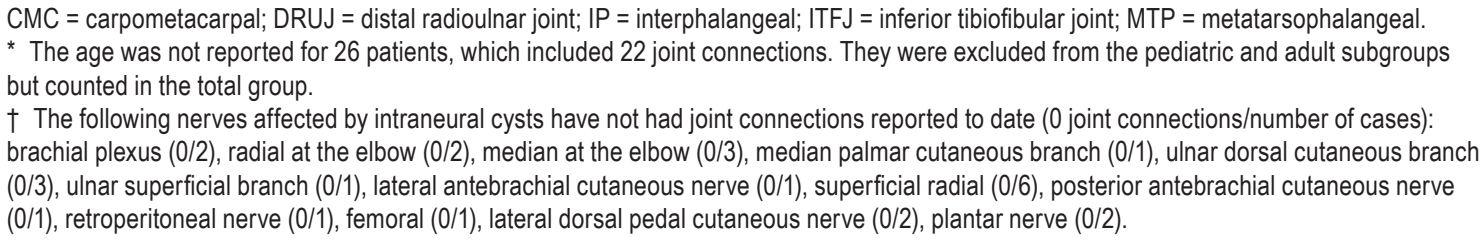 } \\
\hline
\end{tabular}

TABLE 5. Summary of cyst recurrence or persistence per type of surgical treatment and associated recurrence rate*

\begin{tabular}{lccc}
\hline \multicolumn{1}{c}{ Type of Surgery } & Pediatric (\%) & Adult (\%) & Total (\%) \\
\hline Percutaneous aspiration & $1(100)$ & $2(67)$ & $3(75)$ \\
\hline Percutaneous aspiration \& steroid injection & $1(100)$ & $0(0)$ & $1(50)$ \\
\hline Decompression & $0(0)$ & $3(50)$ & $3(38)$ \\
\hline Cyst incision \& evacuation & $3(21)$ & $18(21)$ & $21(21)$ \\
\hline Partial cyst resection & $0(0)$ & $1(5)$ & $1(4)$ \\
\hline Complete cyst resection & $8(20)$ & $27(10)$ & $35(11)$ \\
\hline Cyst incision \& evacuation \& ligation of articular branch & $1(13)$ & $1(3)$ & $2(4)$ \\
\hline Cyst resection \& ligation of articular branch & $0(0)$ & $1(3)$ & $1(3)$ \\
\hline Type of surgery not specified & $0(0)$ & $6(32)$ & $7(28)$ \\
\hline Total & $14(17)$ & $59(11)$ & $74(11)$ \\
\hline
\end{tabular}

* The age was not reported for 26 patients, which included 1 cyst recurrence. This patient was excluded from the pediatric and adult subgroups but counted in the total group. 
TABLE 6. Multivariate logistic regression analysis to identify risk factors for cyst recurrence*

\begin{tabular}{lllc}
\hline \multicolumn{1}{c}{ Parameter } & OR & p Value & $95 \% \mathrm{Cl}$ \\
\hline Age & 0.98 & 0.0277 & $0.96-0.99$ \\
\hline Female sex & 1.3 & 0.4735 & $0.7-2.3$ \\
\hline $\begin{array}{l}\text { Failure to disconnect the articular branch } \\
\text { or address the joint }\end{array}$ & 5.3 & 0.0006 & $1.9-22.2$ \\
\hline
\end{tabular}

* The surgical treatment groups included: 1) failure to disconnect the articular branch or address the joint and 2) surgical treatment included disconnecting the articular branch or addressed the joint.

image or two is quite remarkable, in some cases even obtained using first-generation MRI units. Ironically, in some figures in the reports, the arrow depicting the cyst was actually pointing to the joint connection. In addition, we found unrecognized joint connections in all 16 cases where full MRI series were randomly sampled from papers previously published at other locations reported by other groups in which a joint connection was not identified by the original authors. Many of these cases were purposefully gathered by us to challenge the applicability of the theory in cases of apparent outliers, which in turn advanced our understanding. Such outliers included examples with several interconnected intraneural cysts, ${ }^{122,141}$ or "extreme" cysts (i.e., those with unusual extensions far from a joint, such as ones extending from the STFJ to buttock, shoulder to neck, or elbow to chest). ${ }^{21,52,112,118,141,169} \mathrm{We}$ acknowledge several outliers that remain in the literature which have limited ${ }^{99,159}$ or no imaging ${ }^{1}$ in which we still believe that a joint connection is present.

Our own extensive clinical experience with this entity has demonstrated a joint connection in all cases at different sites - not only the many cases we have reported but an additional cohort of 40 other unreported cases treated by our group or seen in consultation that were not included in this paper. Based on our literature review and clinical experience, we strongly believe that with meticulous scrutiny, the articular (synovial) theory can explain all cases of intraneural ganglia.

Not finding joint connections is understandable. Consistent with inattentional blindness, ${ }^{106}$ we miss things if we are not looking for them. Even if these connections are looked for, they are often small. Several imaging and surgical pitfalls have been described to highlight avoidable scenarios that can help clinicians increase diagnostic accuracy and joint connection recognition for cysts. ${ }^{133}$ Not fully imaging the associated joint or full extent of the lesion can

TABLE 7. Multivariate logistic model to identify risk factors for cyst recurrence using the surgical treatment groups 1) open surgery and 2) percutaneous aspiration

\begin{tabular}{lrcc}
\hline \multicolumn{1}{c}{ Parameter } & OR & p Value & $95 \% \mathrm{Cl}$ \\
\hline Age & 1.0 & 0.0608 & $1.00-1.02$ \\
\hline Female sex & 1.2 & 0.4940 & $0.7-2.2$ \\
\hline Percutaneous aspiration & 12.6 & 0.0035 & $2.4-93.8$ \\
\hline
\end{tabular}
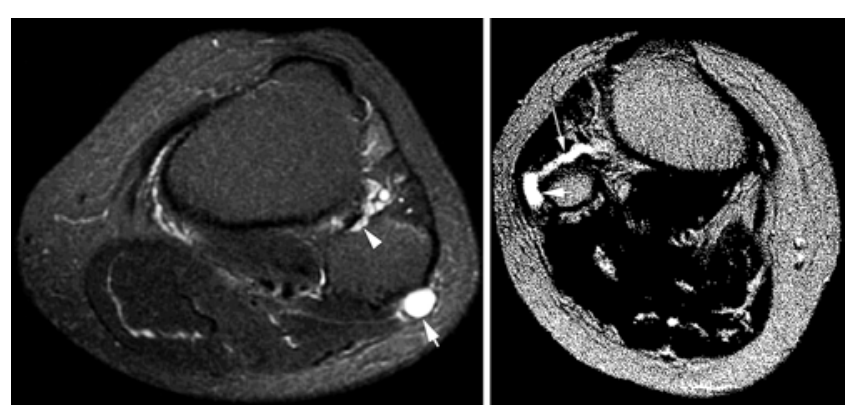

FIG. 4. Previously reported cases with new joint connection. Left: Axial T2-weighted fat-saturated MR image of the leg at the level of the midfibular head demonstrates cyst in the common peroneal nerve (arrow). A previously unrecognized classic "tail sign" is seen on this image (arrowhead). Modified from Hahn SB, Choi CJ, Kang HJ: [Intraneural ganglion of the peroneal nerve-a report of 3 cases.] J Korean Orthop Assoc 41:163-166, 2006 (Korean). Published with permission. Right: Axial non-fat-saturated T2-weighted MR image demonstrating a "transverse limb" sign ${ }^{146}$ (thin arrow) in this example of a peroneal intraneural ganglion (arrow). The finding of cyst within the articular branch is classic and diagnostic of the joint-related nature of the intraneural ganglion despite the low-quality reproduction of the original image in its published form. Modified from Park GY, Bae JH, Lee SY, Lee SM, Kong KS: [Common peroneal nerve palsy caused by an intraneural ganglion-a case report.] J Korean Acad Rehab Med 30:289-293, 2006 (Korean). Published with permission.

easily lead to missing these small joint connections; highresolution MRI with a limited field of view, small skip and slice thickness, and 3D fat-saturated fluid sequences can help. Modern MRI at high resolution is typically acquired with 3 planes, and the examination is comprised of hundreds of images and is adequate to diagnose a cyst and joint connection. The use of arthrography also demonstrated the direct communication between neighboring joint and intraneural cyst in all patients who received this study. $28,30,44,72,80,96,119,139,141,142,144,145,148,151,152$ However, despite
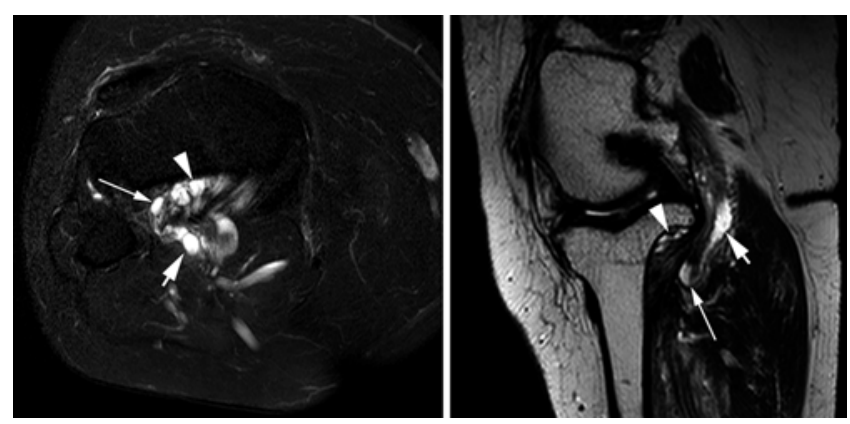

FIG. 5. Previously reported case, which on reinterpretation by our group, demonstrates a joint connection. Axial fat-saturated (left) and sagittal non-fat-saturated (right) T2-weighted MR images of the knee demonstrate a tibial intraneural ganglion cyst (arrows). A "tail sign" is demonstrated arising from the posterior aspect of the tibiofemoral joint (arrowhead) from a lobulated ganglion cyst. The tubular cyst extends from the joint connection to the tibial nerve in a U-shaped configuration typical of an articular nerve branch (thin arrow). The cyst appearance and its joint connection are quite similar to that of a case published by our group. ${ }^{151}$ The bony deformities from the patient's dwarfism are apparent (see also the case report by Choi and Kwon ${ }^{22}$ ). Images courtesy of T. W. Choi and H. K. Kwon. 


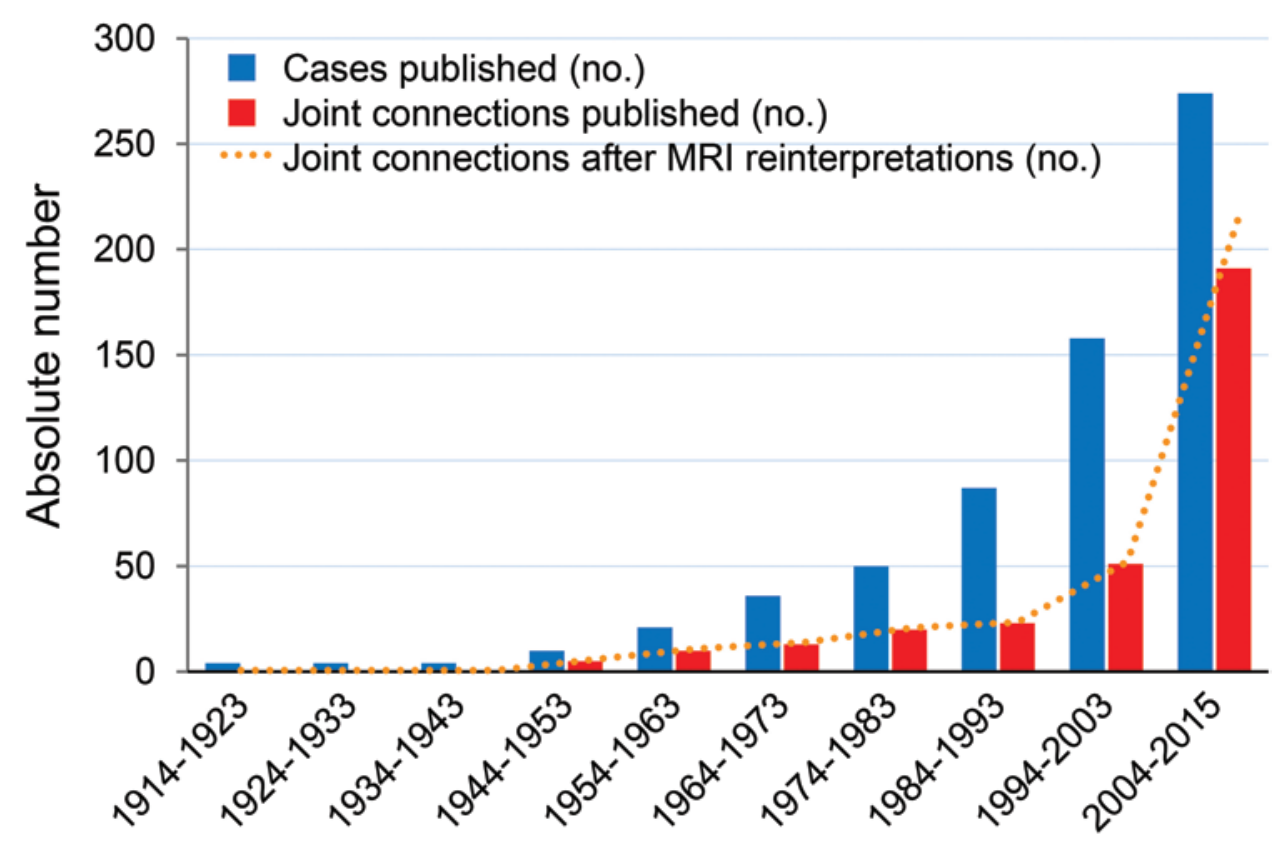

FIG. 6. Graph showing the number of published cases of intraneural ganglion cysts and reported joint connections per decade studied. An increasing trend is seen with the number of published cases of intraneural ganglion cysts (blue columns) and joint connections (red columns) per each successive decade before the articular theory (1914-2003) and time since (2004-2015). More joint connections were identified in the years 2004-2015 compared with the previous 90 years of this study (1914-2003) (statistically significant difference). The yellow dotted line represents the total number of joint connections found after MRI reinterpretations in Part 2 of our study.

the fact that our group has utilized advanced imaging techniques to help visualize joint connections, we have come full circle to show that even routine modern imaging can be used: understanding the existence of these joint connections is the first, and in our opinion the most important, step to avoid pitfalls in identifying them. Furthermore, an incomplete surgical dissection-not adequately displaying the entire anatomy, including the articular branch as it penetrates into the joint capsule-can also understandably lead to unappreciated joint connections.

Based on the articular (synovial) theory, while the articular branch serves as a conduit for cyst fluid propagation toward the parent nerve, the neighboring joint is the inciting factor for intraneural cyst formation. As shown in our cases and others, many joints associated with intraneural cysts are degenerative. ${ }^{69,83,86,88-90,107,124,141,147,149,160,161,175}$ Trauma, which was identified in $13 \%$ of patients, has also been found to play a role in intraneural ganglion cyst formation. Either direct articular trauma ${ }^{17}$ or an indirect mechanism of injury, such as a torsional load applied away from the joint can cause a capsular defect that permits cyst fluid extravasation. ${ }^{16,127,145}$

We believe that the articular (synovial) theory fits with the principle of Occam's razor and provides a single logical explanation for the formation of not only intraneural ganglion cysts but all para-articular cysts. It seems intuitive to us to invoke one theory to explain all cases rather than several different theories. Knowledge of detailed articular branch innervation is tantamount to the theory, ${ }^{55}$ and we appreciate that additional studies are needed at many joints. Application of this information not only can explain unusual cases but also predict nonexistence of intraneural cysts. For example, a case from the inferior tibiofibular joint that would not be immediately obvious can be explained. ${ }^{114}$ Conversely, the absence of cases affecting the superficial peroneal nerve alone at the STFJ (despite the large number of peroneal nerve cysts at the fibular neck) can be understood by its lack of an articular branch to the STFJ. We have shown that separate synchronous or metachronous intraneural cysts affecting different nerves at the same anatomical location are derived from the same joint, ${ }^{131}$ which would explain a previous case of ipsilateral intraneural cysts affecting both the digital radial and dorsal collateral nerves of the thumb. ${ }^{43}$ It seems likely that joint-connected intraneural ganglion cysts also exist in the spine $^{140}$ and cranium but have been confused with extraneural ganglion cysts. ${ }^{8,34,40,94,123,126}$ The more common extraneural/extra-adventitial ganglion cysts also arise from neighboring joints and can sometimes be mistakenly identified as intraneural or adventitial. Recently, our group has also demonstrated robust evidence to support the articular (synovial) theory as the etiology of cystic adventitial disease in arteries and veins, ${ }^{29,129}$ an entity analogous to intraneural ganglion cysts. Finally, several cysts can form at the same time from the same joint, as demonstrated with a complex cyst from the STFJ or ulnohumeral joint leading to an intraneural, extraneural, and intraosseous cyst, ${ }^{135,137}$ or combinations of intraneural and adventitial cysts from the STFJ. ${ }^{54,142,149}$

The other 2 major theories that have been put forth we believe can be dismissed. The tumoral theory suggests that intraneural cysts are formed from the transformation of 
pre-existing tumors into cystic lesions..$^{25,45,50,61,78}$ This theory has been largely rejected based on the lack of pathological and histological proof. The de novo degenerative theory, which is based on the premise that intraneural ganglion cysts are formed spontaneously from a degenerative process affecting nerves, has been applied to cases with unidentified joint connections. ${ }^{3,20,23,33,37,43,73,169}$ In effect, the degenerative theory is a theory of exclusion-one invoked when authors fail to find an articular connection. This degenerative theory in our opinion fails to provide a logical explanation for all cases: if it were true, then intraneural cysts could occur away from joints, such as in the midportion of limbs; in fact, we have shown that these extreme cysts also have joint connections (see previous discussion). As even more clinicians become aware of the existence of joint connections with intraneural ganglion cysts, we believe that all will be recognized, subsequently ending the controversy regarding their etiology.

\section{Surgical Management}

The surgical treatment of intraneural ganglion cysts has also been controversial, likely a consequence from the contention surrounding their pathogenesis. Understanding the etiology of these lesions has allowed for the refinement of surgical techniques. ${ }^{77,132,138}$ Contrary to the most popular form of treatment (cyst resection) or even a more radical approach (nerve resection with or without nerve grafting or nerve transfer), $, 14,17,18,23,24,48,57,78,91,95,104,105,108,155,162,164,171$ we recommend treating the articular branch connection and/or the joint. Even with isolated nerve transfer, ${ }^{91}$ the articular branch remains connected to the neighboring joint, which would conceivably allow for cyst recurrence. We have shown that addressing the articular branch by ligating or disconnecting it near the joint or treating the articular pathology prevents intraneural cyst recurrence. Failure to disconnect the articular branch or treat the joint pathology has been found to be a statistically significant risk factor for cyst recurrence. In fact, we identified only 3 cases of intraneural cyst recurrence or persistence $(3 \%)$ following articular branch disconnection among 112 patients that were treated with either articular branch disconnection, surgery to the joint, or both. ${ }^{12,84,85}$ In 1 case, cyst recurrence was explained by failure of disconnecting the articular branch near the joint. An attempt was made at ligating and transecting the articular branch, but it was not done in close proximity to the joint. This allowed the articular branch joint connection to remain, which permitted intraneural cyst recurrence that propagated along the persistent articular branch, but in a different direction. ${ }^{12}$ Furthermore, percutaneous aspiration should be avoided as a method of definitive care, given its high recurrence rate (4 [67\%] of 6 cases). Percutaneous aspiration was found to be a statistically significant risk factor for cyst recurrence in comparison with open surgery. Analogously, as with intraneural ganglion cysts, a high recurrence rate $(9 \%)$ was found in patients with cystic adventitial disease when the articular (vascular) branch was not identified and in patients treated with percutaneous surgery rather than open surgery $(\mathrm{p}<0.0001) .{ }^{29}$

It is important to recognize that by not addressing the associated joint itself, the origin of cyst formation remains, permitting the continued development of other para-articular cysts. Our experience and the literature review identified several cases of extraneural cyst formation following intraneural cyst treatment, even though they were not specifically researched in this study. ${ }^{58,69,72,95,124,133,149,166}$ Treatment of the joint (cyst origin) can effectively remove the possibility for all para-articular cyst development. It is for this reason that STFJ resection has become a critical part of surgery for STFJ-associated intraneural cysts. Some have even advocated a proximal fibulectomy to treat initial complex ganglion cysts of the STFJ with intraneural involvement or for recurrent disease. ${ }^{49}$ While we recognize that not all joints are as expendable as the STFJ, it is important to anticipate the possible formation of extraneural cysts following intraneural cyst treatment despite articular branch disconnection around nonexpendable joints.

Moreover, we believe that addressing the joint connection and/or the joint pathology may obviate the need for cyst/nerve decompression. It is unknown whether concomitant cyst decompression, however, facilitates nerve recovery by expediting the nerve decompression or cyst resolution. If cyst decompression is part of the surgical plan, iatrogenic nerve injury can be avoided by concomitant simple cyst incision and evacuation of the mucinous fluid to decompress the cyst instead of more radical procedures, such as full cyst excision.

\section{Limitations}

There are several limitations to this study. Despite our aggressive attempt to summarize the world's literature, we acknowledge the reality that we have missed some cases of intraneural ganglia in our search or had some data mistranslated. We understand that all intraneural cysts are not necessarily intraneural ganglion cysts, thus we limited our study to the past 102 years and more modern pathological descriptions. We also purposefully excluded examples of intraneural ganglia when they were admixed with and not distinguished from extraneural ganglia in series of ganglia affecting nerve. All of the articles provided Level IV evidence in the form of either case series or case reports, and complete uniform data were inconsistently reported. Therefore, many patients were excluded from the regression analyses. We recognize the limitations of performing univariate and multivariate statistical analyses based on a review of case reports that contain a large amount of heterogeneity. Publication bias likely exists, given that case reports typically favor rare occurrences while ignoring more common aspects, which may under-represent the norm. All of the data do not currently fully support the articular theory for universal application. Despite the fact that these cysts are all para-articular, joint connections were not reported uniformly. Most cases that had published MR images only showed 1 or several images. The quality of many of the published figures reviewed was marginal or suboptimal because of the technique of the MRI or of the article reproduction from libraries either as hard copy or a pdf file. The lack of regimented long-term clinical and radiological follow-up likely underestimates the true recurrence rate. The reporting of postoperative functional outcomes was highly diversified and frequently incomplete, which, combined with an incomplete follow- 
up rate, makes comparing operative techniques for postoperative results difficult. Finally, and most importantly, a lack of experience of surgeons and radiologists with this entity leads to missed joint connections. While the aim of this interpretation was to establish the applicability of the articular theory, we fully acknowledge our inherent bias given our strong belief in this theory. In fairness, in the majority of cases, we could not confirm that a stated joint connection was present and connected to the specified joint, as the supportive images or operative findings were typically not published. Only through international collaboration can we work together to remedy these limitations and definitively answer some of the remaining unanswered questions.

\section{Conclusions}

This systematic review provides a comprehensive summary of the data and a modern perspective on intraneural ganglion cysts. This study can serve as a baseline for future investigations. With further refinement of surgical techniques, improved neurological outcomes can be assessed in the literature retrospectively and of course prospectively. We believe that the articular (synovial) theory explains the formation of these lesions. Surgical management should be directed toward either the joint or joint connection (articular branch). By following these principles, both the risk of iatrogenic nerve injury and cyst recurrence can be avoided with improved patient outcomes.

\section{Acknowledgments}

We are appreciative of the assistance from Dr. Kimberly K. Amrami and her continued support for the advances made with MRI interpretations of this entity and from Alice McKinney for the illustration. We are grateful to the Center for Clinical and Translational Science (Mayo Clinic, Rochester, Minnesota) as well as to Dr. Tarun D. Singh for their help with statistical analysis. We are thankful to those who helped with article translation: Dr. Michaela Durigova, Laszlo Kupcsik, Elif Bilgic, Mia Esser, Dr. Kerstin Tiedemann, Dr. Suenghwan Jo, Dr. Jenny Ko, Dr. Yoshiaki Itoigawa, Dr. Stepan Capek, Ursula Kielbowicz, Dr. Kasia Lenz, Dr. Andrea Petrucci, Dr. Diana Angius, and Roman Baran. We are also grateful for the collaborative spirit of the many surgeons who have shared MR images with us for this study.

\section{References}

1. Adamek D, Jägers C, Hejnold M, Jach R, Galarowicz B: Intraneural pseudocyst (so-called ganglion) in an unusual retroperitoneal periadnexal location? Diagn Pathol 9:150, 2014

2. Al Mufargi YS, Mouch CA, Ziebarth K, Joeris A, Slongo T: An unusual cause of paralysis of the peroneal nerve: a report of 3 cases. J Pediatr Orthop 31:e50-e52, 2011 (Retracted in J Pediatr Orthop 32:748, 2012)

3. Allieu PY, Cenac PE: Peripheral nerve mucoid degeneration of the upper extremity. J Hand Surg Am 14:189-194, 1989

4. Aprin H, Weinberg J, Lustrin ES, Abrutyn D: Peroneal nerve palsy due to an intraneural ganglion: a case report of a 4 1/2-year-old boy. Am J Orthop 36:E40-E42, 2007

5. Arnold PM, Oldershaw JB, McDonald LW, Langer BG: Myxomatous cyst of the brachial plexus. Case report. J Neurosurg 73:782-784, 1990

6. Bakshi N, Chan KM, Wirganowicz PZ: Peroneal intraneural ganglion. Neurology 65:1753, 2005
7. Balboa O, Viñuela J, Álvarez Y: Casos en imagen 2.Quiste sinovial (ganglión) intraneural en el nervio peroneo común. Radiología 47:297-298, 2005

8. Baldauf J, Junghans D, Schroeder HW: Endoscope-assisted microsurgical resection of an intraneural ganglion cyst of the hypoglossal nerve. J Neurosurg 103:920-922, 2005

9. Bertrand I, Charrier J: Gliome kystique du nerf cubital traité par la résection et la greffe nerveuse. Rev Neurol (Paris) 38:1345-1348, 1922

10. Beauchêne E: in Bulletin de la Faculté de Médecine de Paris, et de la Société établié dans son sein. Paris: Migneret, 1810

11. Bischoff J, Kortmann KB, Engelhardt M: [Intraneural ganglion of the peroneal nerve. A case report.] Z Orthop Unfall 148:589-593, 2010 (Ger)

12. Blitz NM, Prestridge J, Amrami KK, Spinner RJ: A posttraumatic, joint-connected sural intraneural ganglion cystwith a new mechanism of intraneural recurrence: a case report. J Foot Ankle Surg 47:199-205, 2008

13. Brandt Corstius H, Nandoe Tewarie RDS: Intraneural ganglion cyst of the tibial nerve in a child. EURORAD. (http:// www.eurorad.org/case.php?id=11433) [Accessed November $6,2015]$

14. Campailla E: [On so-called cystic degeneration of peripheral nerve trunks.] G Psichiatr Neuropatol 95:967-976, 1967 (Ital)

15. Capek S, Koutlas IG, Strasia RP, Amrami KK, Spinner RJ: An inferior alveolar intraneural cyst: a case example and an anatomical explanation to support the articular theory within cranial nerves. J Neurosurg 122:1433-1437, 2015

16. Cesmebasi A, Howe BM, Amrami KK, Spinner RJ: Expanding the spectrum of indirect trauma and superior tibiofibular joint-related intraneural ganglion cysts. Clin Anat 27:1130-1132, 2014 (Letter)

17. Cesmebasi A, Howe BM, Amrami KK, Spinner RJ: Sequential MR imaging demonstrates evolution of a fibular intraneural ganglion cyst after knee dislocation. Clin Anat 28:2-4, 2015 (Letter)

18. Chang TC, Shih JT: Intraneural ganglion of the ulnar nerve. Formosan J Musc Dis 3:108-110, 2012

19. Chen WA, Barnwell JC, Li Y, Smith BP, Li Z: An ulnar intraneural ganglion arising from the pisotriquetral joint: case report. J Hand Surg Am 36:65-67, 2011

20. Chick G, Alnot JY, Silbermann-Hoffman O: Intraneural mucoid pseudocysts. A report of ten cases. J Bone Joint Surg Br 83:1020-1022, 2001

21. Choi SH, Kim CH, Kim MO, Jung HY: [Intraneural ganglion of the ulnar nerve - a case report.] J Korean Assoc EMG Electrodiagn Med 1:222-225, 1999 (Korean)

22. Choi TW, Kwon HK: [An intraneural ganglion cyst involving the tibial nerve: a case report.] J Korean Assoc EMG Electrodiagn Med 15:98-102, 2013 (Korean)

23. Parkes A: Intraneural ganglion of the lateral popliteal nerve. J Bone Joint Surg Br 43-B:784-790, 1961

24. Coakley FV, Finlay DB, Harper WM, Allen MJ: Direct and indirect MRI findings in ganglion cysts of the common peroneal nerve. Clin Radiol 50:168-169, 1995

25. Cutler EC, Gross RE: Neurofibroma and neurofibrosarcoma of peripheral nerves unassociated with Recklinghausen's disease: A report of twenty-five cases. Arch Surg 33:733779,1936

26. Dartiguenave P: Les Pseudo-Kystes Mucoides du Nerf Sciatique Poplite Externe [dissertation]. Montpellier, France: University of Montpellier, 1983

27. de Bruijn KMJ, Franssen G, van Ginhoven TM: A stepwise approach to 'groin pain': a common symptom, an uncommon cause. BMJ Case Rep 2013:

28. De Schrijver F, Simon JP, De Smet L, Fabry G: Ganglia of the superior tibiofibular joint: report of three cases and review of the literature. Acta Orthop Belg 64:233-241, 1998 
29. Desy NM, Spinner RJ: The etiology and management of cystic adventitial disease. J Vasc Surg 60:235-245, 245. e1-245.e11, 2014

30. Dubuisson AS, Stevenaert A: Recurrent ganglion cyst of the peroneal nerve: radiological and operative observations. Case report. J Neurosurg 84:280-283, 1996

31. El Demellawy D, Bain J, Algawad H, Provias JP: Inflammatory pseudotumor of the peroneal nerve: case report and literature review. Ann Diagn Pathol 12:44-47, 2008

32. El Demellawy D, Bain J, Provias JP: Inflammatory pseudotumor of the peroneal nerve. Muscle Nerve 36:271-272, 2007 (Letter)

33. Ellis VH: Two cases of ganglia in the sheath of the peroneal nerve. Br J Surg 24:141-142, 1936

34. Etherington-Smith RB, Shaw EH: An intraneural cyst of the eighth cervical nerve. BMJ 1:1286-1287, 1910

35. Evans JD, Neumann L, Frostick SP: Compression neuropathy of the common peroneal nerve caused by a ganglion. Microsurgery 15:193-195, 1994

36. Faivre J, Jan M, Ramée MP: Sciatique radiculaire par kyste mucoïde intra-rachidien chez un enfant. Neurochirurgie 21:169-176, 1975

37. Ferguson LK: Ganglion of the peroneal nerve. Ann Surg 106:313-316, 1937

38. Firooznia H, Golimbu C, Rafii M, Chapnick J: Computerized tomography in diagnosis of compression of the common peroneal nerve by ganglion cysts. Comput Radiol 7:343-345, 1983

39. Fontana G, Gallinotto G: [Contribution to the knowledge of pseudocystic tumours of the peripheral nerve trunks.] Riv Ital Ortop Traumatol 5:202-222, 1964 (Ital)

40. Gambhir S, Mujic A, Hunn A: An intraneural ganglion cyst causing unilateral hypoglossal nerve palsy. J Clin Neurosci 18:1114-1115, 2011

41. Gayet LE, Morand F, Goujon JM, Pries P, Clarac JP: Compression of the peroneal nerve by a cyst in a sevenyear-old child. Eur J Pediatr Surg 8:61-63, 1998

42. Gayet LE, Morand F, Goujon JM, Pries P, Clarac JP: [Compression of the peroneal nerve by a synovial cyst in a 7-year-old child.] Rev Chir Orthop Repar Appar Mot 82:762-766, 1996 (Fr)

43. Giele H, Le Viet D: Intraneural mucoid cysts of the upper limb. J Hand Surg Br 22:805-809, 1997

44. Godin V, Huaux JP, Knoops P, Noël H, Rombouts JJ, Stasse P: Une Cause Rare de Paralysie des Muscles Releveurs du Pied: Le Kyste Synovial Intraneural du Nerf Sciatique Poplite Externe. Louv Med 104:281-286, 1985

45. Gomes J, Maia E, Silva R, Abel C, Lemos R, Calhim I: Common peroneal intraneural cyst and neurofibroma: a case report. Eura Medicophys 42 (Suppl 1): 123-124, 2006

46. Gonschorek AS, Fansa H, Plogmeier K, Feistner H: Parese des Nervus peronaeus communis durch ein Ganglion. Aktuelle Neurol 25:74-75, 1998

47. Gosk J, Gutkowska O, Mazurek P, Koszewicz M, Ziółkowski P: Peripheral nerve tumours: 30-year experience in the surgical treatment. Neurosurg Rev 38:511-521, 2015

48. Gosk J, Rutowski R, Zimmer K, Rabczyński J: Intraneural ganglions-different microsurgical strategies. Case Rep Clin Pract Rev 5:525-528, 2004

49. Gulati A, Lechler P, Steffen R, Cosker T, Athanasou N, Whitwell D, et al: Surgical treatment of recurrent proximal tibio-fibular joint ganglion cysts. Knee 21:932-935, 2014

50. Gurdjian ES, Larsen RD, Lindner DW: Intraneural cyst of the peroneal and ulnar nerves. Report of two cases. $\mathbf{J}$ Neurosurg 23:76-78, 1965

51. Hahn SB, Choi CJ, Kang HJ: [Intraneural ganglion of the peroneal nerve: a report of 3 cases.] J Korean Orthop Assoc 41:163-166, 2006 (Korean)
52. Harbaugh KS, Tiel RL, Kline DG: Ganglion cyst involvement of peripheral nerves. J Neurosurg 87:403-408, 1997

53. Hasturk AE, Basmaci M, Canbay S, Harman F, Erten F: Painful lumbosacral plexopathy due to ganglion cyst: magnetic resonance image findings and treatment. J Musculoskeletal Pain 21:75-78, 2013

54. Hébert-Blouin MN, Pirola E, Amrami KK, Wang H, Desy NM, Spinner RJ: An anatomically based imaging sign to detect adventitial cyst derived from the superior tibiofibular joint. Clin Anat 24:893-902, 2011

55. Hébert-Blouin MN, Tubbs RS, Carmichael SW, Spinner RJ: Hilton's law revisited. Clin Anat 27:548-555, 2014

56. Hensinger RN, Thompson GH: An unusual cause of paralysis of the peroneal nerve: a report of 3 cases: retraction. $\mathbf{J}$ Pediatr Orthop 32:748, 2012

57. Herrin E, Lepow GM, Bruyn JM: Mucinous cyst of the sural nerve. J Foot Surg 25:14-18, 1986

58. Hersekli MA, Akpinar S, Demirors H, Ozkoc G, Ozalay M, Cesur N, et al: Synovial cysts of proximal tibiofibular joint causing peroneal nerve palsy: report of three cases and review of the literature. Arch Orthop Trauma Surg 124:711-714, 2004

59. Huang SW, Wang WT: Early detection of peroneal neuropathy by ultrasound. Indian J Orthop 48: 104-106, 2014

60. Huaux JP, Malghem J, Maldague B, Noël H, Rombouts JJ, Courtois C, et al: La pathologie de l'articulation péronéotibiale supérieure. Histoires de kystes. A propos de quatre observations. Rev Rhum Mal Osteoartic 53:723-726, 1986

61. Jenkins SA: Solitary tumours of peripheral nerve trunks. J Bone Joint Surg Br 34-B:401-411, 1952

62. Jerath NU, Chen JJ, Miller BJ, Reddy CG: Teaching NeuroImages: intraneural ganglion cyst of the tibial nerve. Neurology 82:e174-e175, 2014

63. Jones J: Intraneural ganglion cyst. Radiopaedia.org. (http:// radiopaedia.org/cases/intraneural-ganglion-cyst) [Accessed November 6, 2015]

64. Juglard G, Le Nen D, Lefevre C, Leroy JP, Le Henaff B: [Synovial cyst of the hip with revealing neurologic symptoms.] J Chir (Paris) 128:424-427, 1991 (Fr)

65. Jung ST, Cho SB, Moon ES, Lee JJ, Kim KH, Yang HK: [Clinical outcomes of the surgical excision of the ganglion cyst causing compressive neuropathy - a review of twelve collected cases.] J Korean Bone Joint Tumor Soc 12:6370, 2006 (Korean)

66. Kabukçuoglu Y, Kabukçuoglu F, Kuzgun U, Oztürk I: Compression neuropathy of the peroneal nerve caused by a ganglion. Am J Orthop 26:700-702, 1997

67. Kitagawa R, Kim D, Reid N, Kline D: Surgical management of obturator nerve lesions. Neurosurgery 65 (4 Suppl):A24-A28, 2009

68. Krishnan KG, Schackert G: Intraneural ganglion cysts: a case of sciatic nerve involvement. Br J Plast Surg 56:183186,2003

69. Kushida K, Takahashi S, Ando T, Takami H: [A case of intraneural ganglion of the ulnar nerve.] Clin Orthop Surg 16:900-903, 1981 (Jpn)

70. Kwon OS, Bahk WJ, In Y: Common peroneal nerve palsy caused by a ganglion. Case report. J Korean Orthop Assoc 38:531-534, 2003

71. Lacour-Petit MC, Lozeron P, Ducreux D: MRI of peripheral nerve lesions of the lower limbs. Neuroradiology 45:166170,2003

72. Lagarrigue J, Robert R, Resche F, Sindou M, Lazzerini P: [Intraneural synovial cysts of the common peroneal nerve.] Neurochirurgie 28:131-134, 1982 (Fr)

73. Lavarde G: [Mucoid pseudocysts of the peripheral nerves.] J Chir (Paris) 95:97-104, 1968 (Fr)

74. Le Breton C, Fénelon G, Garreau de Loubresse C: Un kyste mal placé. Lettre Rhumatol 279:30-31, 2002 
75. Liang T, Panu A, Crowther S, Low G, Lambert R: Ultrasound-guided aspiration and injection of an intraneural ganglion cyst of the common peroneal nerve. HSS J 9:270274, 2013

76. Linell EA: On solitary fibromyxomata of peripheral nervetrunks, with a description of a case of cystic fibromyxoma of the median nerve. Br J Surg 10:202-206, 1922

77. Lipinski LJ, Rock MG, Spinner RJ: Peroneal intraneural ganglion cysts at the fibular neck: the layered " $U$ " surgical approach to the articular branch and superior tibiofibular joint. Acta Neurochir (Wien) 157:837-840, 2015

78. Lohmeyer JA, Kimmig B, Gocht A, Machens HG, Mailänder P: Combined manifestation of a neurofibroma and a nerve sheath ganglion in the ulnar nerve after radiotherapy in early childhood. J Plast Reconstr Aesthet Surg 60:1338-1341, 2007

79. Lowenstein J, Towers J, Tomaino MM: Intraneural ganglion of the peroneal nerve: importance of timely diagnosis. Am J Orthop 30:816-819, 2001

80. Malghem J, Vande berg BC, Lebon C, Lecouvet FE, Maldague BE: Ganglion cysts of the knee: articular communication revealed by delayed radiography and CT after arthrography. AJR Am J Roentgenol 170: 1579-1583, 1998

81. Masciocchi C, Innacoli M, Cisternino S, Barile A, Rossi F, Passariello R: Myxoid intraneural cysts of external popliteal ischiadic nerve. Report of 2 cases studied with ultrasound, computed tomography and magnetic resonance imaging. Eur J Radiol 14:52-55, 1992

82. Meena UK, Sharma YK, Saini N, Meena DS, Aggarwal A, Chouhan A: Intraneural ganglion of digital nerve of thumb: a case report and review of literature. $\mathbf{J}$ Hand Microsurg $7: 127-128,2015$

83. Menge M, Tachibana S: [Intraneural compression of the ulnar nerve caused by a ganglion of the tendon sheath. A case report.] Handchirurgie 12:15-17, 1980 (Ger)

84. Merkulov VN, , Dorokhin AI, Imyarov SD: [Intraneural ganglion as the cause of compression-ischemic lesion of peroneal nerve in children.] Vestnik travmatologii i ortopedii im NN Priorova 3:76-80, 2014 (Russian)

85. Muramatsu K, Hashimoto T, Tominaga Y, Tamura K, Taguchi T: Unusual peroneal nerve palsy caused by intraneural ganglion cyst: pathological mechanism and appropriate treatment. Acta Neurochir (Wien) 155:1757-1761, 2013

86. Murotani K, Yagata Y, Murao K, Hayashi O, Niwa T, Asano Y: [A case of intraneural ganglion of the ulnar nerve.] Orthop Surg Traumatol 31:1613-1616, 1988 (Jpn)

87. Nakamichi K, Tachibana S: Intraneural ganglion of the branchial plexus. J Hand Surg [Br] 23:123-125, 1998

88. Nakamura T, Takahashi C, Miyashita H, Masuda A, Miki T, Ichiji M: [A case of ulnar nerve palsy due to intraneural ganglion.] Orthop Surg 29:799-802, 1978 (Jpn)

89. Nakayama M, Kawashima H, Horiuchi Y, Yamamoto S, Yamagata T, Kihara M: [Cubital tunnel syndrome with a rapid paralysis by an intraneural ganglion of the ulnar nerve: a case report.] Orthop Surg 57:1603-1606, 2006 (Jpn)

90. Narabayashi Y, Fujita M, Motokawa S, Sumi M, Fujimoto $\mathrm{K}$ : [Intraneural ganglion of the ulnar nerve-a case report.] Orthop Trauma 45:602-604, 1996 (Jpn)

91. Nath RK, Lyons AB, Paizi M: Successful management of foot drop by nerve transfers to the deep peroneal nerve. $\mathbf{J}$ Reconstr Microsurg 24:419-427, 2008

92. Nikolopoulos D, Safos G, Sergides N, Safos P: Deep peroneal nerve palsy caused by an extraneural ganglion cyst: a rare case. Case Rep Orthop 2015:861697, 2015

93. Nokes SR, Pierce WB, Carfagno JJ, Beadle BA, Yocum JH: Radiological case of the month. Peroneal nerve ganglion cyst. J Ark Med Soc 93:257-258, 1996
94. Nonaka Y, Grossi PM, Filomena CA, Friedman AH, Fukushima T: Unilateral hypoglossal nerve palsy caused by an intraneural ganglion cyst. J Neurosurg 113:380-383, 2010

95. Ogose A, Hotta T, Kawashima H, Yamagiwa H, Endo $\mathrm{N}$, Umezu H: Teaching NeuroImages: recurrence of a sural intraneural ganglion cyst after sural nerve resection. Neurology 83:e95-e96, 2014

96. Omoumi P, de Gheldere A, Leemrijse T, Galant C, Van den Bergh P, Malghem J, et al: Value of computed tomography arthrography with delayed acquisitions in the work-up of ganglion cysts of the tarsal tunnel: report of three cases. Skeletal Radiol 39:381-386, 2010

97. Park DY, Lee SY, Han KJ: [Intraneural ganglion of the digital nerve of the hand: a case report.] J Korean Soc Microsurg 20:78-81, 2011 (Korean)

98. Park GY, Bae JH, Lee SY, Lee SM, Song KS: [Common peroneal nerve palsy caused by an intraneural ganglion - a case report.] J Korean Acad Rehab Med 30:289-293, 2006 (Korean)

99. Park JE, Park JH, Chung CW, Lee JS, Kim KB: [A rare case report of huge ganglion cysts involving tibial and sural nerve.] J Korean Assoc Pain Med 12:87-91, 2013 (Korean)

100. Patel P, Schucany WG: A rare case of intraneural ganglion cyst involving the tibial nerve. Proc Bayl Univ Med Cent 25:132-135, 2012

101. Pedrazzini M, Pogliacomi F, Cusmano F, Armaroli S, Rinaldi E, Pavone P: Bilateral ganglion cyst of the common peroneal nerve. Eur Radiol 12:2803-2806, 2002

102. Peng F, Yang JY, Yu C, Wu P, Zhang L, Huang SM, et al: [Clinical reports of intraneural cyst of ulnar nerve at the elbow.] Chin J Hand Surg 29:195-197, 2013 (Chinese)

103. Ramelli GP, Nagy L, Tuncdogan E, Mathis J: Ganglion cyst of the peroneal nerve: a differential diagnosis of peroneal nerve entrapment neuropathy. Eur Neurol 41:56-58, 1999

104. Ratanshi I, Clark TA, Giuffre JL: Novel nerve transfer for the treatment of peroneal nerve palsy secondary to an intraneural ganglion: case report and review. Presented at the Annual Meeting for the American Society for Peripheral Nerve, Kauai, Hawaii, 2014 (Poster) (http://peripheralnerve. org/meeting/abstracts/2014/images/P16.pdf) [Accessed November 6, 2015]

105. Rezzouk J, Durandeau A: [Nerve compression by mucoid pseudocysts: arguments favoring an articular cause in 23 patients.] Rev Chir Orthop Reparatrice Appar Mot 90: 143-146, 2004 (Fr)

106. Rock I, Linnett CM, Grant P, Mack A: Perception without attention: results of a new method. Cognit Psychol 24:502 534,1992

107. Saito H, Tazaki K, Komiyama T, Morimoto R, Ikegami H: [A case of intraneural ganglion of the ulnar nerve presenting with cubital tunnel syndrome.] J Jpn Soc Surg Hand 18:249, 2001 (Jpn)

108. Sanger J, Cortes W, Yan JG: Intraneural ganglion of the suprascapular nerve: case report. J Hand Surg Am 31:4044, 2006

109. Schilg L, Hägele-Link S, Felbecker A, Gers B, Weber J, Tettenborn B, et al: Nervensonographie intraneuraler Ganglien als Ursache schmerzhafter N.-peronaeus-Paresen: eine Fallserie. Praxis (Bern) 103:1433-1438, 2014

110. Speese JJ: Cyst of the median nerve. Ann Surg 61:761762,1915

111. Speese JJ: Cyst of the median nerve. Tr Philadelphia Acad Surg 18:49-50, 1916

112. Spinner RJ: The longest intraneural ganglion cyst: it's not about size but principle(s). J Plast Reconstr Aesthet Surg 67:e69-e70, 2014 
113. Spinner RJ, Amrami KK: Digital intraneural ganglia. J Plast Reconstr Aesthet Surg 65:138-139, 2012 (Letter)

114. Spinner RJ, Amrami KK: Superficial peroneal intraneural ganglion cyst originating from the inferior tibiofibular joint: the latest chapter in the book. J Foot Ankle Surg 49:575578, 2010 (Letter)

115. Spinner RJ, Amrami KK, Angius D, Wang H, Carmichael SW: Peroneal and tibial intraneural ganglia: correlation between intraepineurial compartments observed on magnetic resonance images and the potential importance of these compartments. Neurosurg Focus 22(6):E17, 2007

116. Spinner RJ, Amrami KK, Hamlat A: Collaborative followup. Acta Neurochir (Wien) 150:93-96, 2008 (Letter)

117. Spinner RJ, Amrami KK, Ibrahim Elshiekh MA, Blitz NM: Sural intraneural ganglion cysts are joint-related. Arch Plast Surg 39:77-79, 2012

118. Spinner RJ, Amrami KK, Kliot M, Johnston SP, Casañas J: Suprascapular intraneural ganglia and glenohumeral joint connections. J Neurosurg 104:551-557, 2006

119. Spinner RJ, Amrami KK, Rock MG: The use of MR arthrography to document an occult joint communication in a recurrent peroneal intraneural ganglion. Skeletal Radiol 35:172-179, 2006

120. Spinner RJ, Amrami KK, Tehli O: Re: pure peroneal intraneural ganglion cyst. Hindsight is 20/20. Turk Neurosurg 22:527-528, 2012 (Letter)

121. Spinner RJ, Amrami KK, Wang H, Kliot M, Carmichael SW: Cross-over: a generalizable phenomenon necessary for secondary intraneural ganglion cyst formation. Clin Anat 21:111-118, 2008

122. Spinner RJ, Amrami KK, Wolanskyj AP, Desy NM, Wang $\mathrm{H}$, Benarroch EE, et al: Dynamic phases of peroneal and tibial intraneural ganglia formation: a new dimension added to the unifying articular theory. J Neurosurg 107:296-307, 2007

123. Spinner RJ, Atkinson JL, Maus TP: Intraneural ganglion. J Neurosurg 113:1331-1333, 2010 (Letter)

124. Spinner RJ, Atkinson JL, Scheithauer BW, Rock MG, Birch R, Kim TA, et al: Peroneal intraneural ganglia: the importance of the articular branch. Clinical series. J Neurosurg 99:319-329, 2003

125. Spinner RJ, Atkinson JL, Tiel RL: Peroneal intraneural ganglia: the importance of the articular branch. A unifying theory. J Neurosurg 99:330-343, 2003

126. Spinner RJ, Carmichael SW, Atkinson JL: Intraneural ganglion cyst. J Neurosurg 104:990-992, 2006 (Letter)

127. Spinner RJ, Crnkovich F, Ahmed Ibrahim Kobeal M, Amrami KK: Can trauma cause tibial intraneural ganglion cysts at the superior tibiofibular joint? Clin Anat 25:785787, 2012 (Letter)

128. Spinner RJ, Dellon AL, Rosson GD, Anderson SR, Amrami KK: Tibial intraneural ganglia in the tarsal tunnel: Is there a joint connection? J Foot Ankle Surg 46:27-31, 2007

129. Spinner RJ, Desy NM, Agarwal G, Pawlina W, Kalra M, Amrami KK: Evidence to support that adventitial cysts, analogous to intraneural ganglion cysts, are also joint-connected. Clin Anat 26:267-281, 2013

130. Spinner RJ, Desy NM, Amrami KK: Cystic transverse limb of the articular branch: a pathognomonic sign for peroneal intraneural Ganglia at the superior tibiofibular joint. Neurosurgery 59:157-166, 2006

131. Spinner RJ, Desy NM, Amrami KK: Sequential tibial and peroneal intraneural ganglia arising from the superior tibiofibular joint. Skeletal Radiol 37:79-84, 2008

132. Spinner RJ, Desy NM, Rock MG, Amrami KK: Peroneal intraneural ganglia. Part I. Techniques for successful diagnosis and treatment. Neurosurg Focus 22(6):E16, 2007

133. Spinner RJ, Desy NM, Rock MG, Amrami KK: Peroneal intraneural ganglia. Part II. Lessons learned and pitfalls to avoid for successful diagnosis and treatment. Neurosurg Focus 22(6):E27, 2007

134. Spinner RJ, Edwards PK, Amrami KK: Application of three-dimensional rendering in joint-related ganglion cysts. Clin Anat 19:312-322, 2006

135. Spinner RJ, Harish S, Amrami KK: An historical perspective on ulnar intraneural ganglion cysts and their joint origins. Hand (NY) 9:395-398, 2014

136. Spinner RJ, Hébert-Blouin MN, Amrami KK: The articular origin of peroneal intraneural ganglia. Eur J Orthop Surg Traumatol 20: 177-178, 2010

137. Spinner RJ, Hébert-Blouin MN, Amrami KK: A complex cyst characterized into its individual components: a shared pathogenesis from the superior tibiofibular joint. J Surg Orthop Adv 19:143-148, 2010

138. Spinner RJ, Hébert-Blouin MN, Amrami KK, Rock MG: Peroneal and tibial intraneural ganglion cysts in the knee region: a technical note. Neurosurgery 67 (3 Suppl Operative):ons71-ons 78, 2010

139. Spinner RJ, Hébert-Blouin MN, Dahm DL, Amrami KK: Two different pathways for suprascapular intraneural ganglion cysts along two distinct articular branches from the glenohumeral joint. Clin Anat 23:462-465, 2010 (Letter)

140. Spinner RJ, Hébert-Blouin MN, Maus TP, Atkinson JL, Desy NM, Amrami KK: Evidence that atypical juxtafacet cysts are joint derived. J Neurosurg Spine 12:96-102, 2010

141. Spinner RJ, Hébert-Blouin MN, Rock MG, Amrami KK: Extreme intraneural ganglion cysts. J Neurosurg 114:217224, 2011

142. Spinner RJ, Hébert-Blouin MN, Skinner JA, Amrami KK: Knee MR arthrographic proof of an articular origin for combined intraneural and adventitial cysts. Acta Neurochir (Wien) 152:919-923, 2010

143. Spinner RJ, Hébert-Blouin MN, Tanaka S, Amrami KK, Swartz KR, Fee DB, et al: Hip- and pelvic-related intraneural ganglia. J Neurosurg 112:1353-1356, 2010 (Letter)

144. Spinner RJ, Hébert-Blouin MN, Trousdale RT, Midha R, Russell SM, Yamauchi T, et al: Intraneural ganglia in the hip and pelvic region. Clinical article. J Neurosurg 111:317-325, 2009

145. Spinner RJ, Ibrahim Elshiekh MA, Tubbs RS, Turner NS III, Amrami KK: Posttraumatic torsional injury as an indirect cause of fibular intraneural ganglion cysts: case illustrations and potential mechanisms. Clin Anat 25:641-646, 2012

146. Spinner RJ, Luthra G, Desy NM, Anderson ML, Amrami KK: The clock face guide to peroneal intraneural ganglia: critical "times" and sites for accurate diagnosis. Skeletal Radiol 37:1091-1099, 2008

147. Spinner RJ, Mokhtarzadeh A, Schiefer TK, Krishnan KG, Kliot M, Amrami KK: The clinico-anatomic explanation for tibial intraneural ganglion cysts arising from the superior tibiofibular joint. Skeletal Radiol 36:281-292, 2007

148. Spinner RJ, Puffer RC, Skinner JA, Amrami KK: The MRI appearance and importance of the "very" terminal branches of the recurrent articular branch in fibular intraneural ganglion cysts. Clin Anat 24:268-272, 2011

149. Spinner RJ, Scheithauer BW, Desy NM, Rock MG, Holdt FC, Amrami KK: Coexisting secondary intraneural and vascular adventitial ganglion cysts of joint origin: a causal rather than a coincidental relationship supporting an articular theory. Skeletal Radiol 35:734-744, 2006

150. Spinner RJ, Vincent JF, Wolanskyj AP, Scheithauer BW: Intraneural ganglion cyst: a 200 -year-old mystery solved. Clin Anat 21:611-618, 2008

151. Spinner RJ, Wang H, Angius D, Malik AG, Malghem J, Amrami KK: A modern perspective on the earliest description of an intraneural ganglion cyst arising from the knee joint. Clin Anat 24:106-112, 2011 (Letter) 
152. Spinner RJ, Wang H, Hébert-Blouin MN, Skinner JA, Amrami KK: Sciatic cross-over in patients with peroneal and tibial intraneural ganglia confirmed by knee MR arthrography. Acta Neurochir (Wien) 151:89-98, 2009

153. Spinner RJ, Wang H, Howe BM, Colbert SH, Amrami KK: Deep ulnar intraneural ganglia in the palm. Acta Neurochir (Wien) 154:1755-1763, 2012

154. Srour R, Boyer P, Oesterle H, Stilhart B, Coscia S, Scheremet R: [Mucoid pseudocyst of the common peroneal nerve. Value of MRI (report of a case).] Neurochirurgie 42:66-70, 1996 (Fr)

155. Stamatis ED, Manidakis NE, Patouras PP: Intraneural ganglion of the superficial peroneal nerve: a case report. J Foot Ankle Surg 49:400.e1-400.e4, 2010

156. Suh JS: [Peroneal nerve palsy by recurred intraneural ganglion - one case report.] J Korean Soc Foot Surg 6:242246, 2002 (Korean)

157. Sureka J, Panwar S: MR imaging of suprascapular neuropathies. J Musculoskelet Res 15:1230003, 2012

158. Tagliafico A, Damasio MB, Zuccarino F, Pignataro NMR, Bianchi S, Martinoli C: US and MR imaging of peroneal intraneural ganglia: emphasis on the articular branch. Ultrasound Med Biol 32:178, 2006

159. Takada T, Uratsuji M, Sya N, Yamazaki K, Kurihara A: [Two cases of the intraneural ganglion.] Chubu J Orthop Traumatol 40:915-916, 1997 (Jpn)

160. Tanaka Y, Cho R, Kanai A, Tashiro A: [Case of ulnar nerve paralysis caused by intraneural ganglion.] Seikei Geka 20:1575-1576, 1969 (Jpn)

161. Tang SH, Wang K, Zuo LX, Xu TB, Jie F: [Ganglion cyst combined with nerve cyst causing cubital tunnel syndrome: a case report.] Chinese J Misdiagnosis 2009:1395-1396, 2009 (Chinese)

162. Tatagiba M, Penkert G, Samii M: [Ganglia of peripheral nerves.] Zentralbl Neurochir 54:171-173, 1993 (Ger)

163. Thakur A, Agrawal R, Gupta R, Kotwal V, Bajwa MK: Intraneural cyst of common peroneal nerve-a case report. Medico-Legal Update 11:9-10, 2011

164. Uchida A, Horiguchi A, Ide H, Hatakeyama N, Yoshimura I, Ogawa Y: Mucoid pseudocyst of the obturator nerve. Int J Urol 13:471-472, 2006

165. Usui Y, Harada Y, Mizuno K, Hirohata K: [Infraspinatus muscle paralysis by a suspected intraneural ganglion. A case report.] Rinnshouseikei 20:887-891, 1985 (Jpn)

166. Varela Hernández A, Mendoza Rivera E, López Delgado H, Vega Basulto S, Medrano García R: Presentación inusual de ganlión del nervio ciático poplíteo externo. Neurocirugia 11:137-139, 2000

167. Visser LH: High-resolution sonography of the common peroneal nerve: detection of intraneural ganglia. Neurology 67:1473-1475, 2006

168. Visser LH: High-resolution sonography of the common peroneal nerve: detection of intraneural ganglia. Ultrasound Q 23:41-42, 2007
169. Wadstein T: Two cases of ganglia in the sheath of the peroneal nerve. Acta Orthop Scand 2:221-230, 1932

170. Wang H, Terrill RQ, Tanaka S, Amrami KK, Spinner RJ: Adherence of intraneural ganglia of the upper extremity to the principles of the unifying articular (synovial) theory. Neurosurg Focus 26(2):E10, 2009

171. Warren R: Ganglion of the common peroneal nerve. Ann Surg 124:152-155, 1946

172. West SA: Peroneal intraneural ganglion. Neurology 67:367, 2006 (Letter)

173. Xu Q, Chen Z, Dellon AL, Zhang F: Microsurgical principles related to excision of intraneural ganglion at the elbow. Hand (NY) 9:214-216, 2014

174. Yamazaki H, Saitoh S, Seki H, Murakami N, Misawa T, Takaoka K: Peroneal nerve palsy caused by intraneural ganglion. Skeletal Radiol 28:52-56, 1999

175. Yasuda K, Yuasa K, Matsuki T, Sato D: [A case report of cubital tunnel syndrome due to intraneural ganglion of ulnar nerve.] Tohoku Arch Orthop Surg Traumatol 45:86-89, 2001 (Jpn)

176. Yoneyama R, Sugihara T, Shimizu K, Miyamoto S, Tanaka T, Beppu M: [Intraneural ganglion of common peroneal nerve: a case report.] J East Jpn Assoc Orthop Traumatol 18:185-188, 2006 (Jpn)

\section{Disclosures}

The authors report no conflict of interest concerning the materials or methods used in this study or the findings specified in this paper.

\section{Author Contributions}

Conception and design: Spinner. Acquisition of data: all authors. Analysis and interpretation of data: Spinner, Desy, Howe. Drafting the article: Desy. Critically revising the article: Spinner. Reviewed submitted version of manuscript: all authors. Approved the final version of the manuscript on behalf of all authors: Spinner. Statistical analysis: Desy. Administrative/technical/material support: Wang. Study supervision: Spinner.

\section{Supplemental Information \\ Online-Only Content}

Supplemental material is available with the online version of the article.

Appendices 1-3. http://thejns.org/doi/suppl/10.3171/2015.9. JNS141368.

\section{Correspondence}

Robert J. Spinner, Department of Neurologic Surgery, Mayo Clinic, 200 1st St. SW, Rochester, MN 55905. email: spinner. robert@mayo.edu. 